\title{
Are Older Citizens Using the E-MOI portal in Saudi Arabia, Hail City: A Quantitative Study
}

\author{
Prof. Jyoti Choudrie \\ University of Hertfordshir \\ j.choudrie@herts.ac.uk
}

\author{
Adel Alfalah \\ University of Hertfordshire \\ aas131@hotmail.com
}

\author{
Dr. Neil H. Spencer \\ University of Hertfordshire \\ N.h.spencer@herts.ac.uk
}

Prof. David Sundaram

The University of Auckland

$\underline{\text { d.sundaram } @ \text { auckland.ac.nz }}$

\begin{abstract}
ICT has been widely exploited as a powerful tool of development and prosperity. Therefore, Governments are increasingly moving their civil products and services online. However, there are several groups within societies that are missing out on government benefits due to no online access orland knowledge, including the elderly. This research attempts to understand the factors affecting older adults' adoption and use of e-government in a vicinity of Saudi Arabia. To achieve this, a quantitative method used an online survey questionnaire resulting in 937 completed responses. The findings offer implications for existing literature on e-Government adoption, for practitioners and policy makers.
\end{abstract}

\section{Introduction to the research problem}

Since the end of the $20^{\text {st }}$ century, governments and institutions around the world have been appreciating the benefits of information and communication technologies (ICTs) and technological innovations that have led to the development of broadband infrastructure around the globe. Many governments no longer depend on conventional channels for providing their services to stakeholders. Instead, due to significant ICT investments there is a large reliance on online environments becoming the primary portal of interaction with citizens. This transition to an online government products and service is simply known by the term electronic government (e-government). Simply stated, Egovernment is defined as "the delivery of government services and information electronically 24 hours per day, seven days per week" [1]. The main aim of egovernment is to create transparent, effective and convenient online interaction channels between the government and other official agencies (G2G), the government and businesses (G2B), and finally the
Government and citizens (G2C). G2C is the egovernment aspect that this study focuses on [2]. However, as governments and citizens alike move forward towards the advanced age of Internet and eservice provision, there are some society segments of society that are left behind in technological isolation with no or minimal online presence, such as older adults [3]. This division is generally known as the digital divide. What has also been found is that individuals who are the focal beneficiaries of online services provided by government are the least able to adapt to modern ICT, including the Internet [4]. Furthermore, e-government and technological isolation of older adults has only received marginal attention from researchers, especially in the context of developing nations. This motivated us to investigate and understand the factors by which older adults' adoption and use of e-government in the vicinity of Saudi Arabia are affected. The e-service that this research emphasises is the ministry of interior (MOI) website which is the main government e-platform (https://www.moi.gov.sa). This platform offers a wide range of online services that are diverse including passports, driving licenses, car registrations renewals, traffic violations, pilgrimage permissions and many other civil services. To familiarise readers, the next section provides a literature review, followed by a description of the conceptual model, the hypothesis, and the research methodology and closes with conclusion, limitations, and future research.

\section{Literature}

\subsection{Older Adults}

Within the e-government literature, there are varying definitions for the term 'older adults'. For the purposes of this study, older adults are identified as individuals in the age ranges of 50 years old and above [5]. The rising importance and attention towards elderly citizens is due to the increasing life expectancy. Thanks to technological health advancements and life style improvements, which are 
leading to better qualities of life, countries around the globe have older adults' population than ever before [3]. In terms of elderly populations, Saudi Arabia is no exception as demographic characteristics have been changing where the life span is increasing and fertility is decreasing [6]. In 2013, nearly $4.3 \%$ of the total population in Saudi Arabia was between 55 and 64 years old. It is predicted that by 2050 , the elderly population would comprise approximately $18.4 \%$ of the total Saudi population (ibid).

Older adults are important individuals within societies who desire to feel included and valuable in order to accomplish "successful ageing" [7]. Unfortunately, there is a widespread notion that older people offer only limited contributions to their societies; whereas in reality, older adults offer large economic and social contributions. In the UK for instance, adults aged $65+$ contributed to the economy an overall sum of $£ 40$ billion in 2010 . This is credited to their spending habits and the value of their volunteering [7]. Further, in terms of societal aspects, older adults offer significant contributions to their communities and neighbourhoods due to their continuous and enthusiastic involvement in the places that they reside in. In addition, older people have more tendencies to volunteer and participate in community-based institutions [ibid].

\subsection{Older Adults and Technology Adoption}

As mentioned earlier in the introduction, advancements in ICT have created a gap in society where some people have Internet access and others do not. This distinction between individuals within the same society is widely known as the digital divide [3]. Further, simply having Internet access does not necessarily mean having the ability to use the Internet. The digital exclusion might exist as a result of technology or computer illiteracy, poverty, disability, gender discrimination, language and old age [ibid]. A major cause of the digital divide, age, has been widely identified and recognized in literature [8] [9]. The likelihood of seniors using digital services increases when such services are affordable, accessible and usable [10]. Older adults' adoption of technology is highly dependent on their physical and mental status. The physical dimension refers to health impairments that occur due to aging, such as memory loss and visionary impairments whereas the mental dimension denotes attitudinal aspects, such as privacy worries and security [11].

Digital tools and other ICTs can result in positive change and improvement in older adults' quality of life, and promote more independent ways of living (ibid). These advanced technologies can also provide the elderly with a means of developing their knowledge; for example, obtaining a portal to the world by using the Internet or enhancing their health status using regular exercise programmes offered on smart phones and tablet devices. Another important aspect for the elderly in the contemporary information society is social inclusion. For instance, ICTs such as, tablets devices provide seniors with an ability to interact online with their family and friends using for example, Facebook, Skype (ibid). Therefore, older adults who are able to effectively exploit well-functioning means of ICTs have more advantages over those who do not; thus, the latter group may suffer social isolation (ibid).

\subsection{E-government Adoption and Challenges}

In literature, the topic of e-government and technology diffusion and adoption has been widely investigated and researched by applying various renowned technology acceptance and success models [12]. Models used for e-government research include, the theory of reasoned action by Fishbein \& Ajzen, Diffusion of Innovation by Rogers, the Technology Acceptance model by Davis, IS success models by DeLone \& McLean, Theory of planned behavior by Ajzen, and the Unified Theory of Acceptance and Use of Technology (UTAUT) by Venkatesh, Morris, Davis, \& Davis [ibid].

Generally, literature has identified various factors influencing citizens' adoption of e-government, including social influence, usefulness (relative advantage), anxiety [12], trust in government [13], perceived online risk [14], cultural and privacy issues [15], disposition to trust, security and trust in the Internet [16]. Finally, since e-government is a technological system normally based on the Internet, the digital divide has been identified among the key challenges and barriers towards successful adoption of e-government services [17] [15].

\subsection{E-government Adoption in the Developing World}

A study conducted in Saudi Arabia concerning egovernment adoption by Saudi citizens in the capital city of Riyadh found that age affects users' enthusiasm and willingness to use e-government services. Further, although education levels of individuals influenced e-government adoption, it was less important than the factor of age. Finally, factors such as, knowledge of the Internet and security were significant as they impacted the individual users' perception of e-government [18]. Some of these findings such as the factor of age, education level and 
security were again confirmed by a diverse study examining the adoption of e-government services in Saudi Arabia [19]. Additionally, the study highlighted other factors of impact including, eservice availability, compatibility and complexity.

A Pakistani study investigating the factors facilitating end-user adoption of e-government used the model of UTAUT. Findings revealed that performance expectancy (saving time $\&$ effort), effort expectancy (usefulness, effectiveness \& easiness), and social influence (prestigious image \& family influence) largely influenced citizens' adoption of egovernment in Pakistan [20].

A qualitative study of the adoption of egovernment in Jordan used focus groups to identify that there are many barriers to e-government adoption. These barriers include relative advantage, trust of the Internet, word of mouth (social influence), waste (favoritism), resistance to change, Internet \& computer skills and digital divide [21].

An Omani study of the adoption of e-government found a significant relation between users' adoption of e-government and service quality (efficiency, reliability, responsiveness and security) [22]. It was also statistically proven that some demographic variables (age \& education) have a significant impact on the willingness to adopt e-government (ibid).

In summary, age and level of education are continuously identified as influential factors on egovernment adoption. Further, social influence, service availability, security and efficiency are also aspects many studies have in common as significant factors with regard to e-government adoption in the developing world.

\section{Development of the Conceptual Model and Hypothesis}

As explained earlier, the field of information systems has applied attitude literature in order to understand and establish the link between attitude towards something and action [23], [24]. While literature recognizes the pertinent role of an enduser's attitude, it lacks information on attitude formation [25]. Learning theories of attitude change endeavour to elucidate the mechanisms by which individuals form their attitudes. [26], [27]. Therefore, the current study applies the learning theories of attitude change in order to understand the attitude formation of the elderly towards Saudi Arabia's egovernment channel (MOI e-portal). Learning theories have been embraced and used by various primal theoretical research studies as the foundation for their work, such as the theory of reasoned action (TRA) [25]. Learning theories consist of three key elements of attitude formation, which are social learning (equivalent to social influence in UTAUT \& subjective norms in TAM), operant conditioning, and classical conditioning [28]. The latter is concerned with someone's sociability and friendliness, which is irrelevant to the aim of this study; thus, excluded.

Further, e-commerce literature has widely identified the factors of the Technology Acceptance Model (TAM), Diffusion of Innovation and trustworthiness models as key players with regard to user adoption of e-commerce [29]. The great resemblance between e-commerce and e-government (i.e. the online environment) has validated the assumption that the aforementioned models' factors will also greatly influence adoption of e-government services by citizens [30]. Therefore, it is appropriate to apply some of the aforementioned factors to the current study as it concerns e-government adoption.

The Diffusion of Innovation (DOI) theory is useful for understanding the acceptance of new and novel innovations by users in which diffusion is defined as 'the process by which an innovation is communicated through certain channels over time among the members of a social society' [31]. DOI proposes that an innovation is affected by five major constructs: relative advantage, complexity, compatibility, trialability and observability (ibid). Trialability and observability are of less relevance to adoption research, thus they were excluded [30]. Further, two of TAM's constructs; namely, perceived usefulness $\&$ perceived ease of use are equivalent to the constructs of relative advantage \& complexity of DOI (ibid). Therefore, for this study, TAM was excluded and DOI was applied as it offers similar dimensions that are more comprehensive than TAM.

Additionally, the model of perceived characteristics of innovating (PCI) presented by [32] suggests more aspects affect adoption and use of an innovation. Image is one of the PCI constructs that refers to individual's feeling and opinion of an innovation as a status symbol. Image is also encompassed in [33] TRA, which is the basis for TAM, as subjective norm. Given the great extent of attention web-based systems have gained in the mass media, image is included in this study [30].

Finally, as mentioned above, the study also attempts to understand the link between someone's trust and adoption of governmental web-based services by applying the trustworthiness model. Trust is defined as someone's certainty that a promise made by others in society is trustworthy [34]. TRA is again used as a guiding foundation for the trustworthiness model. TRA proposes that beliefs influence intentions, which in turn influences someone's actions [33]. The applied model in this study includes the constructs of trust of the 
government, trust of the Internet and disposition to trust [35] (figure 1). In conclusion, the study attempts to combine and synthesize the aforementioned theories in an attempt to cover different aspects by which elderlies' adoption is influenced. The following table 1 presents the study hypothesis.

Table 1. Models, Constructs \& Hypotheses

Attitudinal Formation under Learning Theories

Social influence or Primary influence (PI)

P1: PI will positively relate to older adults' intention to use MOI e-Portal.

Perceived cyber risk (PCR)

P2: PCR will negatively relate to older adults' intention to use MOI e-Portal.

Perceived website assistance (PWA)

P3: PWA will positively relate to older adults' intention to use MOI e-Portal Diffusion of Innovation

Compatibility (COM)

P4: Greater levels of perceived COM will positively relate to older adults' intention to use MOI e-Portal.

Relative advantage (RA)

P5: Greater levels of perceived RA will positively relate to older adults' intention to use MOI e-Portal. Image (IM)

P6: Greater levels of perceived IM will positively relate to older adults' intention to use MOI e-Portal. Complexity (COMP)

P7: Lower levels of perceived COMP will positively relate older adults' intention to use MOI e-Portal.

\section{Trustworthiness}

Disposition to trust (DTT)

P8: DTT will positively relate to older adults' trust of the Internet (TOI).

P9: DTT will positively relate to older adults' trust of the government (TOG).

Trust of the Internet (TOI)

P10: TOI will positively relate to older adults' intention to use MOI e-Portal.

Trust of the government (TOG)

P11: TOG will positively relate to older adults' intention to use The MOI e-Portal.

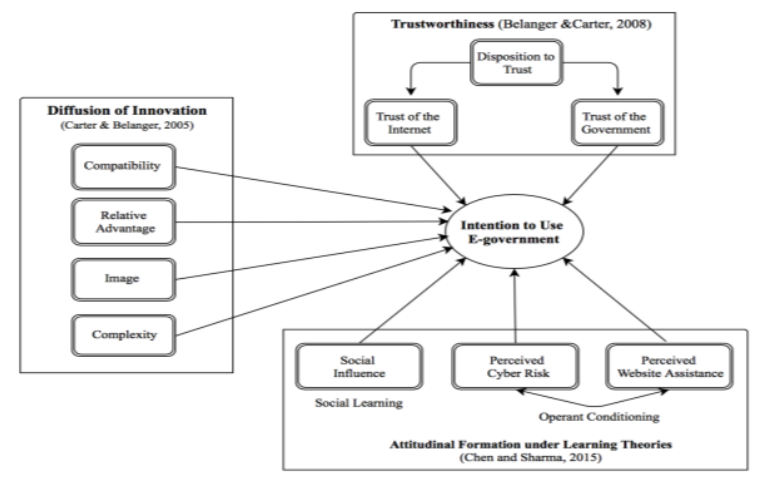

Figure 1: Conceptual Framework of the Research 4. Research Methodology
Data collection for the current study was based on a quantitative approach that used hard copy survey questionnaires consisting of demographics sections and a close ended questionnaire that applied a 7 point Likert scale. Prior to distribution, and during the process of developing the survey, 10 experts of various backgrounds validated the content of the questionnaire.

The research took place between the period of $18^{\text {th }}$ July and $12^{\text {th }}$ October 2016 in the city of Hail in the Kingdom of Saudi Arabia. The city is seen as the capital of the north of Saudi Arabia as it connects other areas in the north with the capital city of Riyadh, the holy city of Mecca, and the southern provinces of the kingdom.

In 2016 , more than $14 \%$ of the total population (total is approximately 700,000) of Hail region fell into the category of older adults $(\leq 50)[36]$. Another reason for the selection of Hail as the research site is the fact that the researcher has established contacts and access to the city.

In order to ensure effective participants recruitment, a combination of a non-random sampling method comprising of self-selection and snowball sampling were applied to reach out to people 50 years old and above. First, the researcher used self-selection approach with already established contacts, followed by snowball sampling in which those contacts helped recruiting more participants from their personal and work contacts. The researcher distributed 1656 questionnaires to potential participants, and received 1147 responses, of which 937 were complete and viewed as valid. Accordingly, a response rate of $56 \%$ was achieved. The response rate is calculated by dividing the number of valid responses by the numbers of the total sample [37]. In literature, a response rate of $50 \%$ and above is considered to be adequate [38]. The next section provides an overview data analysis of this study where brief descriptive analysis of the core socio-economic demographic variables is provided.

\section{Data Analysis \& Findings}

\subsection{Descriptive Analysis}

Before commencing this project, the cultural norm of gender division in Saudi society was recognised, which means that to prevent females underrepresentation, an equal weighting had to be calculated. To ensure that there was equal representation of the genders despite these differences, maintenance of accuracy and to avoid any possible nonresponse bias, this study applied the corrective weighting approach to the gender variables 
where both genders are treated statistically; that is, as if they are equal in number [39], [40]. It is worthwhile nonetheless to identify the original cases of both genders. The number of females comprised $31.3 \%$ (293 cases) of the total sample and the males were $68.7 \%$ (644 cases) respectively.

The following subsection identifies the sociodemographic variables against Internet penetration rates within the elderly of Hail city. The data and tables were analysed and created using the data analysis software package SPSS version 23 .

\subsection{Demographics and Internet Adoption}

Table 2 below shows that $663(70.8 \%)$ of an overall 936 respondents are Internet adopters whereas
$259(27.6 \%)$ respondents are non- adopters. Further, in terms of gender, the number of adopters in the male category is 385 , which comprises $82 \%$ of the total category. Comparatively, 278 respondents of the females are adopters (59\% of total). In terms of age, participants aged between 50-59 years displayed a high Internet penetration rate with a $95.9 \%$ adoption rate, whilst $66.7 \%$ of the contributors within the age category of 60-69 are adopters. Further, in the age groups of 70 years old and over, only $8.1 \%$ of the contributors were Internet adopters.

Additionally, in terms of education, the uneducated respondents showed a $0 \%$ adoption rate. Further, Internet penetration appeared to be reducing as the education levels reduces. For full details, please refer to table 2 below.

Table 2. Gender-Weighted Socio-demographic Summary of Internet Adoption ( $n=937)$

\begin{tabular}{|c|c|c|c|c|c|c|c|c|c|}
\hline \multirow{2}{*}{\multicolumn{2}{|c|}{ Category }} & \multicolumn{2}{|c|}{$\begin{array}{l}\text { Internet } \\
\text { Adopters }\end{array}$} & \multicolumn{2}{|c|}{ Non-Adopters } & \multicolumn{2}{|c|}{$\begin{array}{c}\text { Planning to } \\
\text { become } \\
\text { adopters }\end{array}$} & \multicolumn{2}{|c|}{ Total } \\
\hline & & Cases & $\%$ & Cases & $\%$ & Cases & $\%$ & Cases & $\%$ \\
\hline \multirow{3}{*}{ Gender } & Male & 385 & 82 & 74 & 16 & 9 & 2 & 468 & 50 \\
\hline & Female & 278 & 59 & 185 & 40 & 5 & 1 & 468 & 50 \\
\hline & Total & 663 & 70.8 & 259 & 27.6 & 14 & 1.4 & 936 & 100 \\
\hline \multirow{6}{*}{ Age } & $50-59$ & 308 & 95.9 & 8 & 2.4 & 5 & 1.5 & 321 & 34.2 \\
\hline & $60-69$ & 349 & 66.7 & 166 & 31.7 & 8 & 1.5 & 523 & 55.8 \\
\hline & $70-79$ & 6 & 8.1 & 67 & 90.5 & 1 & 1.3 & 74 & 7.9 \\
\hline & $80-89$ & 0 & 0 & 16 & 100 & 0 & 0 & 16 & 1.7 \\
\hline & Over 90 & 0 & 0 & 2 & 100 & 0 & 0 & 2 & 0.2 \\
\hline & Total & 663 & 70.8 & 259 & 27.6 & 14 & 1.4 & 936 & 100 \\
\hline \multirow{9}{*}{ Education } & Higher Degree & 9 & 100 & 0 & 0 & 0 & 0 & 9 & 0.9 \\
\hline & 1st Degree & 97 & 100 & 0 & 0 & 0 & 0 & 97 & 10.3 \\
\hline & Diploma & 156 & 98.1 & 2 & 1.2 & 1 & 0.6 & 159 & 16.9 \\
\hline & Technical & 15 & 93.7 & 0 & 0 & 1 & 6.3 & 16 & 1.7 \\
\hline & Sec. School & 250 & 91.2 & 22 & 8 & 2 & 0.7 & 274 & 29.2 \\
\hline & Pri. School & 119 & 57.2 & 85 & 40.8 & 4 & 1.9 & 208 & 22.1 \\
\hline & Read and Write & 17 & 12.2 & 116 & 83.4 & 6 & 4.3 & 139 & 14.8 \\
\hline & Illiterate & 0 & 0 & 35 & 97.2 & 1 & 2.7 & 36 & 3.8 \\
\hline & Total & 663 & 70.6 & 260 & 27.7 & 15 & 1.5 & 938 & 100 \\
\hline
\end{tabular}

\subsection{Constructs Reliability \& Validity}

The consistency of the current study's model constructs was established by assessing their reliability [41]. Table 3 depicts three well-known reliability measures; namely, Average Variance Extracted (AVE), composite reliability and Cronbach's Alpha. A value of 0.7 emerged for Composite Reliability and the Cronbach's Alpha, which is considered adequate. For the AVE a value of 0.5 or above emerged, which again suggests sufficiency. Therefore, based on the values shown in table 3 , all the constructs meet the reliability measurement criterion (ibid).

Further, discriminant validity and factor loadings were generated to establish validity of the constructs. All the measurements were adequate and acceptable. However, they were excluded due to page restrictions. The results are available upon request from the authors.

\subsection{Structural Model Analysis}

To analyse the earlier proposed model, Figure 1, the authors used the SmartPLS software package. This software program uses the analysis technique of Partial Least Squares based Structural Equation 
Modelling (PLS-SEM), which was considered suitable for this due to the following reasons: 1) its effectiveness with exploratory research which attempts to explore key target constructs; 2) PLSSEM is also suitable for relatively complex structural models, which comprises many constructs and many items [42].

\subsection{Coefficient of Determination $\left(\mathbf{R}^{2}\right)$}

The Coefficient of Determination $\left(\mathrm{R}^{2}\right)$ indicates the extent to which the independent variables of a model can explain the dependent variable within the same model [42]. The $\mathrm{R}^{2}$ for the key dependent variable (intentions to use) of the model of this study is 0.945 , which means that nearly $94 \%$ of the variability within the elderly's intentions to use the egovernment MOI e-Portal can be explained by the model. Such high $\mathrm{R}^{2}$ values indicate significance and establish sufficient explanatory power (ibid).

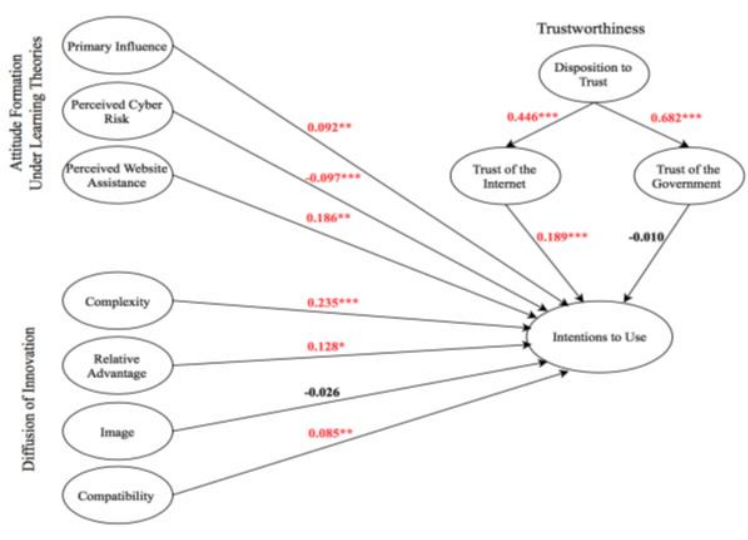

Figure 2. Structural Model Evaluation *Significant at 0.1 levels $\quad * *$ Significant at 0.05 levels $* * *$ Significant at 0.01 levels

Table 3. AVE, Composite Reliability \& Cronbach's Alpha

\begin{tabular}{|c|c|c|c|}
\hline Construct & AVE 1 & Composite Reliability 2 & Cronbach's Alpha 3 \\
\hline COM & 0.948 & 0.982 & 0.973 \\
\hline COMP & 0.907 & 0.980 & 0.974 \\
\hline DTT & 0.667 & 0.888 & 0.830 \\
\hline IM & 0.948 & 0.986 & 0.982 \\
\hline PCR & 0.949 & 0.987 & 0.982 \\
\hline $\mathbf{P I}$ & 0.981 & 0.994 & 0.990 \\
\hline PWA & 0.924 & 0.988 & 0.986 \\
\hline RA & 0.934 & 0.983 & 0.976 \\
\hline TOG & 0.897 & 0.972 & 0.962 \\
\hline TOI & 0.957 & 0.985 & 0.977 \\
\hline UI & 0.957 & 0.985 & 0.978 \\
\hline \multicolumn{4}{|c|}{$\begin{array}{c}1=\text { Satisfactory if }>=0.5,2=\text { Satisfactory if }>=0.7 \\
3=\text { Satisfactory if }>=0.7\end{array}$} \\
\hline
\end{tabular}

values are 1.65 (significance level $=10 \%$ ), 1.96

\subsection{Coefficients and Hypotheses Testing}

A path analysis aids in understanding the impact of the explanatory constructs on the dependent construct. The values between these constructs are called path coefficients in which there are indications of significance (see figure 2). Nevertheless, in order to achieve more consistent evaluation of any assumed significance, bootstrapping was used. Judgement on significance is based on the rules of thumb for structural model evaluation in which "Critical t- (significance level $=5 \%$ ), and 2.58 (significance level $=1 \%$ )" [42]. After applying the aforementioned criterion, 9 out of the 11 hypotheses were supported by the outcomes of the model evaluation with some disparities among them (see Table 4). For example, the constructs of Complexity (COMP) as well as Trust of the Internet (TOI) correlated strongly with the dependent key variable, Intentions to Use (UI). On the other hand, the constructs of Trust of The Government (TOG) as well as Image (IM) showed insignificant correlations with UI. A full model evaluation is available upon request. 
Table 4. Hypotheses Testing Results

\begin{tabular}{|c|c|c|c|}
\hline HN & Hypotheses & Coefficient & Outcome \\
\hline H1 & PI $\rightarrow$ UI & 0.092 & Supported \\
\hline H2 & PCR $\rightarrow$ UI & -0.097 & Supported \\
\hline H3 & PWA $\rightarrow$ UI & 0.186 & Supported \\
\hline H4 & COMP $\rightarrow$ UI & 0.235 & Supported \\
\hline H5 & RA $\rightarrow$ UI & 0.128 & Supported \\
\hline H6 & IM $\rightarrow$ UI & -0.026 & Not Supported \\
\hline H7 & COM $\rightarrow$ UI & 0.085 & Supported \\
\hline H8 & DTT $\rightarrow$ TOI & 0.446 & Supported \\
\hline H9 & DTT $\rightarrow$ TOG & 0.682 & Supported \\
\hline H10 & TOI $\rightarrow$ UI & 0.189 & Supported \\
\hline H11 & TOG $\rightarrow$ UI & -0.010 & Not Supported \\
\hline
\end{tabular}

\section{Discussion and Implications}

\subsection{Demographic Variables, Digital divide and Internet Adoption}

The widespread use of ICT, including the Internet, has widened the technological gap between different groups within societies. This gap has been greatly characterised by various sociodemographic variables, such as age, gender and education level.

For this research we used the understanding that literature has emphasized the role of "old" age being a major cause of the digital divide [3]. In terms of this study, age, which is the main theme of the study, has shown a clear impact on the status of the older adults' adoption of Internet. The data in table 2 clearly shows that "younger adults" have a high Internet diffusion level whereas "senior adults" have almost not adopted the Internet at all. For instance, participants aged between the ages of 50-59, 70-79 and over 80 years show Internet adoption levels of $96 \%, 8 \%$, and $0 \%$ respectively. In other words, as age increases, the likelihood of Internet adoption reduces. To further establish the association between age and Internet adoption, and to examine whether they are independent of each other or not, Fisher's exact test was run on SPSS. Fisher's exact test is used because it does not depend on sample or cell size restrictions [43]. The results in table 5 below show a statistical significance in which $p$-value $<0.001$ confirms the association.
Table 5. Fisher's Exact Test

\begin{tabular}{|l|c|c|}
\hline & Value & $\begin{array}{c}\text { Exact Sig. } \\
(2 \text {-sided })\end{array}$ \\
\hline Fisher's Exact Test & 308.055 & .000 \\
\hline N of Valid Cases & 936 & \\
\hline \multicolumn{2}{|c|}{$\mathbf{P}^{*}<.05 \quad \mathbf{P}^{* *}<.01 \quad \mathbf{P}^{\star * *}<.001$} \\
\hline
\end{tabular}

Secondly, the ability to use the Internet and technology in general is normally associated with a users' level of education, as it requires certain skills. Many studies within the context of both developed and developing countries have emphasized education levels being a major deterrent to Internet and technology adoption [8], [9]. In accordance with the latter statement, the analysis of this study shows a clear link (direct correlation) between education and adoption. For example, respondents with higher and $1^{\text {st }}$ degrees are $100 \%$ Internet adopters, respondents with primary school certificate are $57.2 \%$ Internet adopters, and finally $100 \%$ of illiterate respondents are non-adopters (see table 2).

Finally, gender discrimination is an issue that has been fairly acknowledged in the technology adoption literature [11], [44]. In light of this, the data of this study depicted Internet adoption rate of $82 \%$ amongst males and 59\% amongst females. These ratios might designate an association between gender and Internet adoption. However, it is important to note that the majority of the nonadopter females fall into "less educated" and "senior adults" categories; thus indicating the significance of age and education on gender, not gender per se.

In conclusion, many older adults are caught in the digital gap created by the advance of technology and the inevitability of the Internet. However, societies and governments can provide the opportunity for such elderly adults to increase their use of Internet technology through social policies (financial subsidies, computer provision, frequent exposure to Internet) and training/education (free courses, social networking) [45].

\subsection{Older Adults and E-Government Services}

As an important form of ICT, and to fulfil the aim of this study, e-government services are discussed by examining older adults' adoption of such services in Hail city of Saudi Arabia. As stated in the previous section, this sturbe $23 a s$ confirmed the existence of age-based and 
education-based digital divides. They are both key deterrent phenomena that prevent the elderly from using the Internet and consequently, online government services. This result is in accordance with previous studies concerning e-government adoption in Oman and Saudi Arabia [18], [22].

In terms of the structural model analysis, results show that attitude formation factors have a strong influence on older adults' intention to use egovernment. Such intention correlated with primary influence (PI) by 0.092 (figure 3) which indicates the importance of family and friends with regards to the elderly's perception formation. The attitude of older adults towards e-government is affected negatively or positively based on the opinions of important people in their life about egovernment [20], [21]. Further, perceived cyber risk (PCR) showed a correlation of -0.097 (figure 3 ) that depicts a strong negative association with intention to use e-government. When older adults feel unsafe in an online environment due to their worries of fraudulent activities (e.g. information theft), it is most likely that they will form a very negative perception towards using e-government [14], [18]. As for perceived website assistance (PWA), it seems critical for older adults to receive e-portal assistance if they were to use it. Their intention to use e-government websites correlated with this factor (PWA) by 0.186 (figure 3 ). Due to the probable lack of computer and technology skills, the elderly might require immediate assitance and responsiveness while conducting an online task or receiving an e-governemnt service [22].

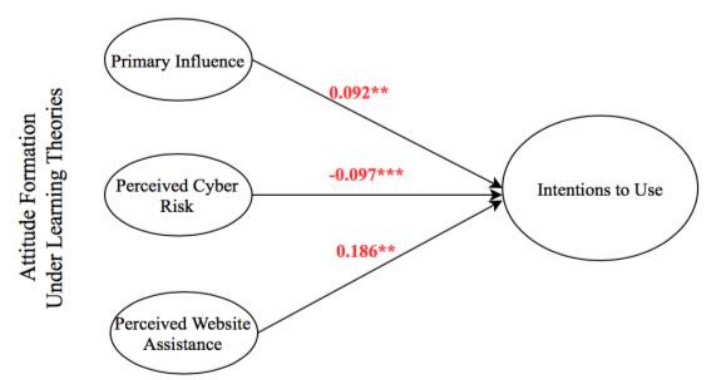

Figure 3. Analysis of Attitude Formation

In addition, three of the four factors derived from the DOI model showed some disparities regarding their impact on older adults' intention to use egovernment. Complexity (COMP) appears to be the most significant factor with a coefficient of 0.235 , followed by compatibility (COM) with a coefficient of 0.085 , and finally relative advantage with 0.128 . Image (IM), the fourth factor, showed insignificant value of -0.026 (figure 4).

The adoption literature has continuously identified the aforementioned factors as influential on e-government adoption. Less complex and easy to use governmental websites will result in a positive perception and more liklihood of being used [19], [20]. Further, compatibility and relative advantage (usefulness) are positive influential factors of e-government adoption [12], [19]. On the other hand, this study found that percieved image from using e-government does not influence older adults' intention to use e-government, which conflicts with the findings of other studies [19]. This might be a result of the way the elderly view life, in which life is more than pursuing prestigious image. Many other studies which found associations between image and e-government adoption, had a sample of young adults or a sample of adults of mixed ages.

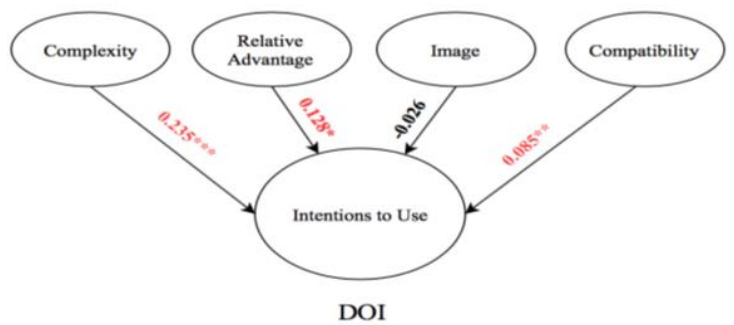

Figure 4. Analysis of Diffusion of Innovation

Finally, the dimensions of trustworthiness are major topics in adoption research. As government services are provided online, users must have trust in both the service provider (government) and the service medium (Internet) [13] [16] [21]. Both of these trust dimensions are in turn affected by disposition to trust, which means the latter has an indirect impact on adoption [16]. In terms of this study, trust of the Internet (TOI) and trust of the government (TOG) correlated with Intention to use by 0.189 and -0.010 respectively. Further, disposition to trust (DTT) correlated with TOI and TOG by 0.446 and 0.682 respectively (figure 5 ).

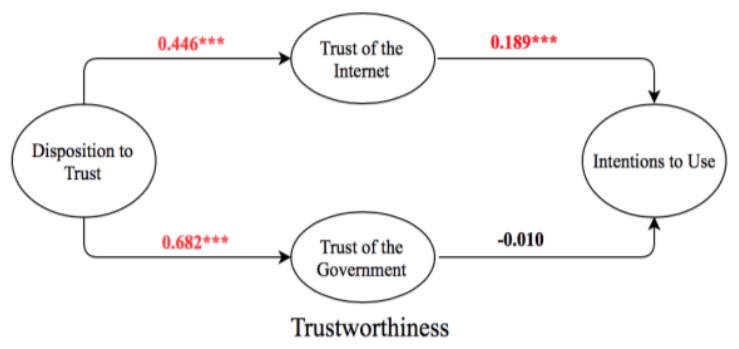

Figure 5. Analysis of Trust Model

These values confirm the important influence of TOI and DTT on older adults' intention to use egovernment. However, the factor of TOG is not supported by the analysis of this study. After revisiting the participants' answers, it is clear that although most particpants tend to trust the government, this percieved trust was not enough of an incentive, and did not appear to affect their intention to use e-government whatsoever. It seems that their perception of e-government is sofefery 
based on Internet trust.

In light of the findings of this study, government should address and acknowledge the concerns and worries of older adults to promote the use of their online services. Robust security measures and privacy assurance should also be made to tackle the concerns of the elderly. Further, provision of free training sessions, increased responsiveness (e.g. 24/7 assistance availability), and reduced website complexity are measures that will help the elderly to deal with any possible difficulties that they might face while using e-government services [22], [46].

\subsection{Implications of this Study}

For academia, this study will enrich the literature concerning e-government and older adults in the Arab world. The literature on e-government and the Arab world lacks studies on older adults and egovernment, more importantly within the context of Saudi Arabia. Further, for government officials, the findings will encourage e-government policy makers to pay more attention to the existing digital divide. It will also raise awareness among policy makers of the difficulties older adults encounter with regards to e-government. As for industry, the study helps service providers by identifying the needs, concerns, and preferences of customers.

\section{Conclusion, Limitations and Future Directions}

The purpose of this study is to explore and understand the factors influencing older adults in Saudi Arabia's adoption and use of e-government in the vicinity of Hail City. The authors used a quantitative approach and disseminated online survey questionnaires to older adults households of Hail city in which 937 completed replies were received. Findings suggested that the digital gap within the older population is mainly characterized by age, gender and education levels. The study adopted the models of Attitudinal Formation, DOI and Trust in order to examine their impact on older adults' intention to use e-government. The results indicated the significance and validity of all propositions except for image and trust of government. Therefore, in order to mitigate the magnitude of digital divide and to encourage the use of e-government by the elderly, government should apply effective social policy procedures, promote awareness of e-government, provide training and enhance online service quality measurements.

The study took place in the city of Hail, which is a medium sized city. Therefore, a limitation of the study is that it lacks the context of smaller rural and larger urban cities. Further, this study examined only a small portion of the whole population and within only few vicinities of Hail city; therefore, generalizations cannot be claimed. As a future direction, researchers should consider either smaller cities in the urban or rural areas, or larger urban and rural cities. Further, this is a quantitative study. Future directions could apply qualitative approaches where various in-depth data collection methods such as, interviews or observations could be applied. Further, as this study was limited to one location, it is possible for other researchers to enrich older adults' literature by conducting similar studies in different cities and locations.

\section{References}

[1] Norris, D. F. Fletcher, P. D. \& Holden, S. H. (2001). Is your local government plugged in? Highlights of the 2000 electronic government survey. Washington, DC: International City/County Management Association.

[2] Klabi, H. Mellouli, S \& Rekik, M. (2016). A reputation based electronic government procurement model. Government Information Quarterly. In Press.

[3] Choudrie, J. Ghinea, G. Songonuga, V. N. (2013). Silver Surfers, E-government and the Digital Divide: An Exploratory Study of London Local Authority Websites and Older Citizens. Interacting with Computers. 25(6), 417-442.

[4] Dugdale, A. Daly, A. Papandrea, F. \& Maley, M. (2005). Accessing e-government: challenges for citizens and organizations. International Review of Administrative Sciences. 71(1), 109-118.

[5] Hanson. V. (2009). Age and Web Access: The Next Generation. Proceedings of the 2009 International Cross-Disciplinary Conference on Web Accessibility (W4A). 7-15.

[6] Nancy, J. Weil, K. \& Felmban, W. (2016). Aging in Saudi Arabia: An Exploratory Study of Contemporary Older Persons' Views About Daily Life, Health, and the Experience of Aging. Gerontology \& Geriatric Medicine V2. 1-9.

[7] Fenton, S. J. \& Draper, H. (2014). Older people make a huge contribution to society. Some communities and faith groups draw on this contribution in responding to the needs of all their members. Birmingham Policy Commission.

[8] BBC. (2003). Digital divide sees elderly left behind. Retrieved from http://news.bbc.co.uk/1/hi/uk politics/2780543.stm.

[9] Warschauer, M. (2004). Technology and Social Inclusion: Rethinking the Digital Divide. The MIT Press. Retrieved from $<\mathrm{https}: /$ goo.gl/ht3v74>.

[10] Iwasaki, N. (2013). Usability of ICT applications for elderly people in disaster reduction. Journal of EGovernance. 36(2), 73-78.

[11] Mostaghel, R. (2016). Innovation and technology for the elderly: Systematic literature review. Journal of Business Research. 69, 4896-4900.

[12] Rana, N. P. \& Dwivedi. Y. K. (2015). Citizen's adoption of an e-government system: Validating extended social cognitive theory (SCT). Government Information Quarterly. 32, 172-181. Page 2360 
[13] Porumbescu, G. A. (2016). Linking public sector social media and e-government website use to trust in government. Government Information Quarterly. 33, 291-304.

[14] Chakraborty, R. Lee, J. Bagchi-Sen, S. Upadhyaya, S. \& Raghav Rao, H. (2016). Online shopping intention in the context of data breach in online retail stores: An examination of older and younger adults. Decision Support Systems, 83, 47-56.

[15] Meijer, A. (2015). E-governance innovation: Barriers and strategies. Government Information Quarterly. 32, 198-206.

[16] Kim, D. Ferrin, D. \& Rao, R. (2008). A trust-based consumer decision-making model in electronic commerce: The role of trust, perceived risk, and their antecedents. Decision Support Systems, 44(2), 544 564.

[17] Van Deursen, A. J. A. M. \& Van Dijk, J. A. G. M. (2011). Internet skills and the digital divide. New media and society, 13(6), 893-911.

[18] Hamner, M. \& Al-Qahtani, F. (2009). Enhancing the case for Electronic Government in developing nations: A people-centric study focused in Saudi Arabia, Government Information Quarterly. 26, 137143.

[19] Alateyah, S. Crowder, R. \& Wills, G. (2013). An Exploratory study of proposed factors to Adopt egovernment Services: Saudi Arabia as a case study. International Journal of Advanced Computer Science and Applications, 4(11), 57-66.

[20] Ahmad, M. O. Markkula, J. \& Oivo, M. (2013). Factors affecting e-government adoption in Pakistan:sepa citizen's perspective. Transforming Government: People, Process and Policy, 7 (2), 225239.

[21] Alomari, M. K. Sandhu, K. \& Woods, P. (2014). Exploring citizen perceptions of barriers to egovernment adoption in a developing countryisep. Transforming Government: People, Process and Policy. 8(1), 131-150.

[22] Sharma, S. K. (2015). Adoption of e-government services: The role of service quality dimensions and demographic variables People. Process and Policy. 9(2), 207-222.

[23] BARKI H \& HARTWICK J. (1994) Measuring user participation, user involvement, and user attitude. MIS Quarterly 18(1), 59.

[24] FRIEDKIN, NE. (2010). The attitude-behavior linkage in behavioral cascades. Social Psychology Quarterly. 73(2), 196-213.

[25] Chen, R, \& Sharma, S. K. (2015). Learning and selfdisclosure behavior on social networking sites: the case of Facebook users. European Journal of Information Systems. 24, 93-106.

[26] Lorge, I. (1936). Irrevelant rewards in animal learning. Journal of Comparative Psychology. 21(1), $105-128$.

[27] Hovland, C. Janice, L. \& Kelley, H. (1953). Communication and Persuasion. Yale University Press, New Haven, CT. [iscep]

[28] Feist, G. \& Rosenberg, E. (2010). Psychology: Making Connections. McGraw-Hill.

[29] Gefen, D. \& Straub, D. (2000) The relative importance of perceived ease of use in IS adoption: a study of e-com- merce adoption. Journal of the Association for Information Systems, 1, 1-28.
[30] Carter, L., \& Bélanger, F. (2005). The utilization of e-government services: citizen trust, innovation and acceptance factors is . Information Systems Journal. $15,5-25$.

[31] Rogers, E. (1995). Diffusion of Innovations. The Free Press, New York, USA.

[32] Moore, G. \& Benbasat, I. (1991). Development of an instrument to measure the perceptions of adopting an information technology innovation. Information Systems Research, 2, 173-191.

[33] Ajzen, I. \& Fishbein, M. (1972). Attitudes and normative beliefs as factors influencing intentions. Journal of Personality and Social Psychology. 21 (1), pp. 1-9.

[34] Rotter, L.B. (1971). Generalized expectations for interpersonal trust. American Psychologist 26 (5), 443-452.

[35] Bélanger, F. \& Carter, L. (2008). Trust and risk in egovernment adoption. Journal of Strategic Information Systems. 17, pp.165-176.

[36] Saudi General Authority for Statistics. (2016). Demographic Survey. Retrieved from. https://www.stats.gov.sa/sites/default/files/ardemographic-research-2016 5.pdf.

[37] Saunders, M. Lewis, P. \& Adrian, T. (2009). Research Methods for Business Students. 5th edn. Financial Times/Prentice Hall, New Jersey.

[38] Nulty, D. D. (2008). The adequacy of response rates to online and paper surveys: what can be done? Assessment \& Evaluation in Higher Education. 33(3), 301-314.

[39] Lahaut, V. Jansen, H. Mheen, D. \& Garretsen, H. (2002). NON-RESPONSE BIAS IN A SAMPLE SURVEY ON ALCOHOL CONSUMPTION. Alcohol and Alcoholism, 37 (3): 256-260.

[40] Nathan Berg (2005). Non-response bias Munich Personal RePEc Archive. Retrieved from https://mpra.ub.uni-muenchen.de/26373/.

[41] Litwin, M.S. (1995). How to Measure Survey Reliabilty And Validity. SAGE Publications.

[42] Hair, J. F., Ringle, C. M., \& Sarstedt, M. (2011). PLS-SEM: Indeed a Silver Bullet. The Journal of Marketing Theory and Practice. 19(2), 139-152.

[43] Lin, J-J. Chang, C-H. \& Pal, N. (2015). A Revisit To Contingency Table And Tests Of Independence: Bootstrap Is Preferred To Chi-Square Approximations As Well As Fisher's Exact Test. Journal of Biopharmaceutical Statistics. 25, 438458.

[44] Niehaves, B. \& Plattfaut, R. (2014). Internet adoption by the elderly: employing IS technology acceptance theories for understanding the age-related digital divide. European Journal of Information Systems, 23(6): 708-726.

[45] Choi. NG, DiNitto. DM. (2013). The Digital Divide Among Low-Income Homebound Older Adults: Internet Use Patterns, eHealth Literacy, and Attitudes Toward Computer/Internet Use. $J$ Med Internet Res.15(5):e93.

[46] Al-Shehry, A. M. (2008). Transformation towards egovernment in The Kingdom of Saudi Arabia: technological and organisational perspectives, $A$ Doctoral Thesis. 